\title{
The Factors Affecting the Affluent Consumers Luxury Purchasing Behavior in China
}

\author{
Xia Wang ${ }^{1} \&$ Luqiong Tong ${ }^{2}$ \\ ${ }^{1}$ School of Business, Renmin University, Beijing, China \\ ${ }^{2}$ Business School, Beijing Normal University, Beijing, China \\ Correspondence: Luqiong Tong, Business School, Beijing Normal University, Beijing, 100875, China. Tel: \\ 86-138-1048-6786. E-mail: tonglq@bnu.edu.cn
}

Received: June 26, 2017

doi:10.5539/ijbm.v12n10p194
Accepted: August 20, 2017 Online Published: September 17, 2017

URL: https://doi.org/10.5539/ijbm.v12n10p194

\begin{abstract}
China is fast becoming one of the most important luxury goods market. The purpose of this study is to investigate the determinants of luxury purchasing behavior in the Chinese affluent market. Based on the logit analysis of 618 affluent respondents, the results show that social-adjustive motivation and life satisfaction are significantly associated with the purchasing of luxuries. However, the value-expressive motivation, which has been verified that could drive the consumer buy luxury items, does not have significant effect on luxury purchasing behavior for the Chinese affluent consumers. In the meantime, the demographic characteristics of individual are significantly associated with his/her luxury purchasing behavior, and the younger affluent consumers with higher income and international education are more likely to buy more luxuries. It helps researchers and companies to understand the differences of the factors influencing luxury consumption between Chinese consumers and their global peers.
\end{abstract}

Keywords: affluent consumer, luxury purchasing behavior, luxury consumption motivation

\section{Introduction}

\subsection{Antecedents of Luxury Consumption in China}

The luxury consumption has been booming since the early 1990s. The size of this market was US $\$ 840$ billion in 2004 and reach 1 trillion in 2010 (Truong, McColl, \& Kitchen, 2009). Due to the growth of this market, it is critical for marketers to understand the reasons why consumers buy luxuries, and how their perception of luxury value affects their buying behavior (Wiedmann, Hennigs, \& Siebels, 2009). Various theories have been proposed to explain why people engage in luxury consumption (e.g. Truong, 2010; Tynan, McKechnie, \& Chhuon, 2010; Vigneron \& Johnson, 1999), which have focused on the consumer psychology of consumption, such as materialism, symbolism, and social identity, little research in the academic literature has investigated the actual purchasing behavior of the consumers. However, the psychology of consumption could not always predict the actual purchasing behavior (e.g. Chintagunta \& Lee, 2012; Wright \& MacRae, 2007), especially for the purchasing of expensive luxuries, as many of the people have a positive attitude and intention towards luxuries, but they could not afford them (Debnam \& Svinos, 2006).

Moreover, with its substantial population and growing economy, China is fast becoming one of the world's largest luxury goods market. According to the report released by the World Luxury Association (WLA) in 2011, the total consumption of luxury products by Chinese consumers accounts for 25 percent of the global market. Especially for the affluent consumer, which have long been recognized as the most important luxury market that could not be ignored. Despite the global downturn in 2008, the number of wealthy households in China continues to grow. By 2015, the country will hold the world's fourth-largest concentration of wealthy people (Atsmon \& Dixit, 2009). The affluent market with higher income would have a higher portion of their income on discretionary consumption, such as luxury goods (Sekulic \& Sibley, 2007). Thus, it is important for the luxury brands to understand the factors behind their purchases. However, little is known about the factors that determine the luxury purchasing behavior of these affluent Chinese consumers.

Therefore, in the present study, we fill this gap by analyzing how various potential antecedents are associated with the actual luxury purchasing behavior in the Chinese affluent market. We examined three types of predictors 
that were included in the model: luxury consumption motivation, life satisfaction, and demographic variables. We predict that these variables may determine the luxury purchasing behavior of affluent Chinese consumers.

\subsection{Literature and Hypothesis}

\subsubsection{Luxury Consumption Motivation}

The growth of luxury market has generated significant academic research interest in the luxury consumption. Why do consumers pursue luxury? Previous studies have tried to answer this question, and find out that luxury-seeking behavior is the result of multiple motivations (Lee \& Hwang, 2010). For instances, Vigneron and Johnson (1999) identified five types of prestige-seeking behaviors, classified as: conspicuous, unique, social, hedonic, and perfectionistic. Wiedmann et al. (2009) explored four dimensions of luxury value, the financial value, the functional value, the individual value, and the social value. Tynan et al. (2010) states that consumers sought a wide range of values, such as utilitarian value, symbolic/expressive value, experimental/hedonic value, relational value, and cost value, from the luxury consumption. Truong (2010) investigates both intrinsic and extrinsic aspirations as antecedents in predicting luxury consumption. Tsai (2005) believes that consumers' orientation towards luxury consumption is affected by self-directed pleasure, self-gift giving, congruity with internal self, and quality assurance. Zhan and He (2012) examines three psychological traits as predictors of attitudes towards luxury brands: value consciousness, susceptibility to normative influence, and the need for uniqueness. Wong and Ahuvia (1998) explored the factors, such as self-concept, conformity pressure, and gift exchange that drives luxury consumption differences between Southeast Asian and Western cultures.

It is generally accepted that the decision to purchase a luxury product depends not only on the material needs satisfied by the product, but also on social needs (Amaldoss \& Jain, 2005). Thus studies of the motivations for luxury consumption fall into two broad categories: social-adjustive motivation and value-expressive motivation. Shavitt (1989) states that consumers' attitudes toward luxury brands may serve a social-adjustive function, a value-expressive function, and both of the motivation are positively related to luxury consumption. The value-expressive function allows the individual to express his or her underlying values and dispositions, and the social-adjustive function was formed on the basis of how well they allow individuals to fit into important social situations and behave in ways appropriate to various reference groups (DeBono, 1987).

Previous researches also suggest that luxury consumption may differ across cultures (e.g. Shukla \& Purani, 2012). In China context, the behavior and understanding on luxuries are different to that for western people. For Chinese people, the culture and history of luxuries are still far behind. Many people buying luxuries for show off, and they focus more on "face" and social value in using luxuries (Li \& Su, 2007; Wong \& Ahuvia, 1998; Zhan \& $\mathrm{He}, 2012$ ). However, as the younger people become the main power of Chinese consumers (Debnam \& Svinos, 2006), which tend to stress individual uniqueness (Bian \& Forsythe, 2012) and eager express themselves through the consumption, the value-expressive motivation may also be important in determining buying luxuries. Building on the previous studies, we expect that:

H1: Social-adjustive motivation is positively related to luxury purchasing behavior.

H2: Value-expressive motivation is positively related to luxury purchasing behavior.

\subsubsection{Life Satisfaction}

In addition to luxury consumption motivation, which are internal, external factors such as life satisfaction and demographic characteristics also contribute to the luxury purchasing behavior. It is widely accepted that life satisfaction is an important component of our life and much of our actions are driven by the pursuit of life satisfaction. Generally, status concerns are an important feature of our social existence. Psychologists and consumer researchers have demonstrated that individuals highly focused on materialistic aims will have lower life satisfaction and happiness (Roberts \& Clement, 2007), thus possessing luxury conveniences, which will fulfill the needs of materialism and higher status, could be a predictor of life satisfaction (Diener et al., 2010).

However, life satisfaction can further drive consumers' actions. People seem more likely to express optimism about their future life if their present life situation is satisfying than if it is not (Oishi, Wyer, \& Colcombe, 2000). If consumers were satisfied with the life, they may have positive expectations of future (MacLeod \& Conway, 2005), which in turn increase their desire for luxuries (Mandel, Petrova, \& Cialdini, 2006). Thus, we expect that:

H3: Life satisfaction is positively related to luxury purchasing behavior.

\subsubsection{Demographic Characteristics}

The trend of the luxury market shows that consumers are not homogeneous. Thus, knowing demographic segments can provide helpful information in understanding consumers' luxury purchasing behavior. The impact 
of demographic characteristics on luxury attitudes have been well documented in literature. For example, Han Nunes, \& Drèze (2010) have divided luxury consumers into four groups according to their financial means and the degree to which status consumption is a motivating force in their behavior. Also low income populations exhibited more unfavorable attitudes toward luxury restaurants than did middle and high income populations (Lee \& Hwang, 2011).We identified four commonly used but important demographic elements as antecedents of luxury purchasing behavior: income, age, educational attainment, and gender.

Income is a concept that is essential in defining the household expenditures for the affluent consumer (Dubois \& Duquesne, 1993). Luxury goods are expensive in relative and absolute terms. Thus the demand of luxury goods may be determined by the income level, we expect that:

H4: Income of the affluent consumer will have an impact on the luxury purchasing behavior. The higher the income, the higher the propensity to buy luxury goods.

Younger people, having grown up in the global era and being avid consumers of media that enable global connectivity, are presumably more world-minded than their older counterparts (Cleveland et al., 2009). In China, the X-Generation (aged 18-35 years with high education and income) has a great preference for foreign products and values (Zhang \& Shavitt, 2003). They report higher on materialistic values and conspicuous consumption than the western young adults (Podoshen, Li, \& Zhang, 2011), and are more materialism than their parents generation (Gu \& Huang, 2009), which drives the increasingly interests on luxury products and fashion. According to the report by WLA, the major consumers of luxury products in China are becoming younger as the new generation shifts their attitude toward life, and people aged between 25 and 30 will become the dominant group of consumers for luxury products in China (Debnam \& Svinos, 2006). Thus we expect that:

H5: Age of the affluent consumer will have an impact on the luxury purchasing behavior. The younger have more propensity to buy luxuries.

The affluent are well-educated, most of them have university degrees or above (Sekulic \& Sibley, 2007), thus we class this market as group who have domestic education background or international education background. Generally, some education is needed to fully appreciate the luxury goods (Dubois, Czellar, \& Laurent, 2005). And the consumers, especially those have the education in foreign countries, are likely to hold a greater desire and economic ability to purchase foreign, status-enhancing product (Cleveland, Laroche, \& Papadopoulos, 2009). We expect that:

H6: Education of the affluent consumer will have an impact on their luxury purchasing behavior. Those have an international education will have more propensity to buy luxury goods than that with domestication education.

Gender can also be an important determinant of luxury purchasing behavior. Drawing on previous studies, males and females have different ways of processing information (Dube \& Morgan, 1996). Males and females have different reasons for purchasing luxury goods. Females are generally more materialistic (Workman \& Lee, 2011) and score higher on conspicuous consumption (Segal \& Podoshen, 2012) than males. Females have a more positive attitudes toward and a higher purchase intentions of luxury brands versus non-luxury brands than males (Stokburger-Sauer \& Teichmann, 2011). Also, the luxury goods found today are more targeted towards women consumers, because luxury buying requires more time and attention as it is a high involvement purchase, which generally is found with female consumers. Thus, we expect that:

H7: Gender will have an impact on luxury purchasing behavior. Female are more likely to buy luxury goods than males.

The conceptual framework is displayed in Figure 1. Thus, we investigate the internal factors of luxury consumption motivation, as well as the external factors of life satisfaction and demographic characteristics, and the impact of these factors on the actual luxury purchasing behavior of Chinese affluent consumers. 


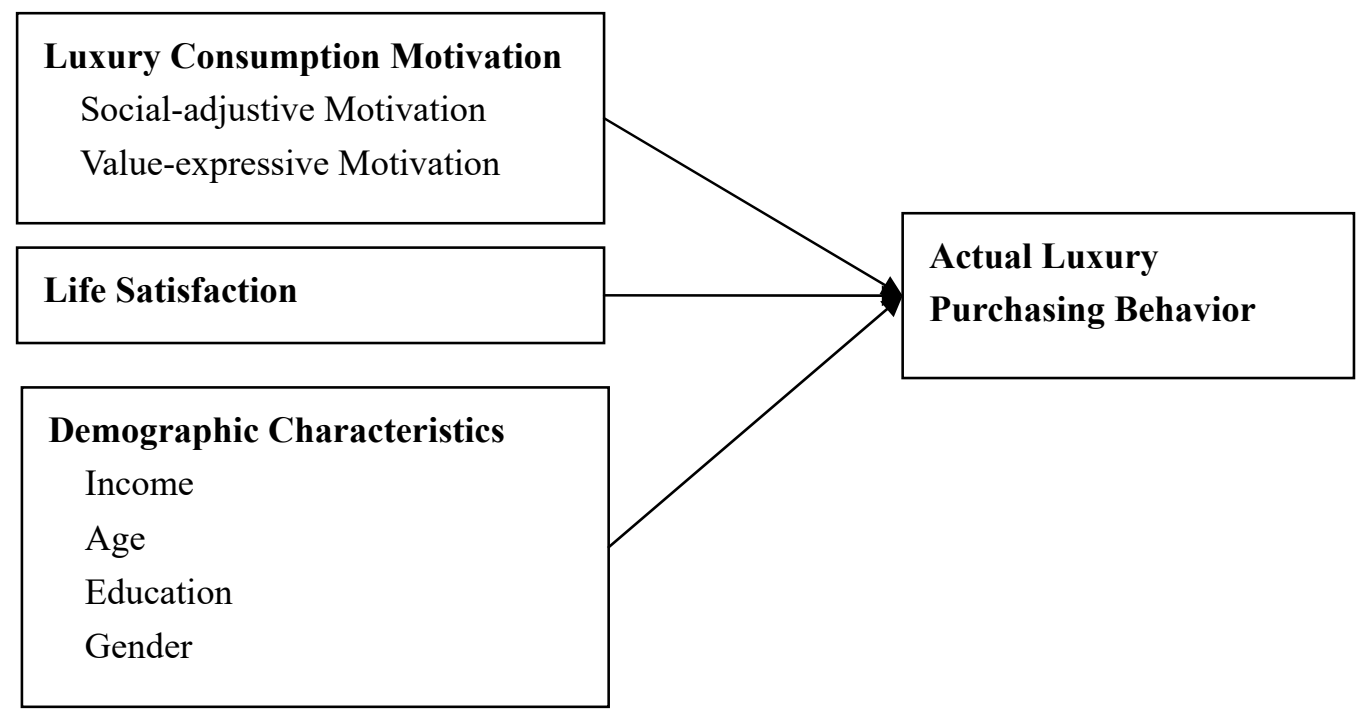

Figure 1. Conceptual framework

\section{Method}

The affluent Chinese mainly resides in major cities (Sekulic \& Sibley, 2007), thus we surveyed the affluent consumers in four major cities of China: Beijing, Shanghai, Guangzhou, and Chengdu. The participants were required to have individual income more than 200,000RMB per year or household income more than 300,000RMB per year. Also the participants were required to be more than 19 years old. Snowball sampling was used to identify potential participants. Snowball sampling means that researchers select the initial sample and then ask that initial sample to recommend others who also meet the criteria. Respondents who successfully completed the questionnaire received $30 \mathrm{RMB}$ worth of gift. The final comprised of 618 participants.

The descriptive statistics was displayed in Table 1. About half of the respondents were male (49.7\%), with 56.9\% below 35 years old. Few of the respondents (15.1\%) got the education abroad. In terms of the individual income per year, $23.8 \%$ of the respondents reported less than 200 thousand RBM per year, $61.7 \%$ reported between 200 and 300 thousand RBM per year, and the others reported exceeds 300 thousand RBM per year. The respondents represent the affluent of the consumers in China (Sekulic \& Sibley, 2007).

Table 1. Demographic Statistics of the Respondents

\begin{tabular}{lll}
\hline Demographics & & $\%$ \\
\hline \multirow{2}{*}{ Gender } & Male & 50.3 \\
& Female & 49.7 \\
& $20-30$ years old & 29.4 \\
Age & $31-35$ years old & 27.5 \\
& $36-45$ years old & 31.1 \\
& More than 45 years old & 12.0 \\
Individual Income per Year & Less than 200,000RMB & 23.8 \\
& 200,000-300,000RMB & 61.7 \\
Education & More than 300,000RMB & 14.6 \\
& International Education & 15.1 \\
Residence & Domestic Education & 84.9 \\
& Beijing & 28.6 \\
& Shanghai & 27.3 \\
& Guangzhou & 27.2 \\
& Chengdu & 16.8 \\
\hline
\end{tabular}

Participants was required to answer whether they have buy a luxury item, such as watches priced more than 10,000RMB, glasses priced more than 3,000RMB, and bags priced more than 5,000RMB etc., in the last year. 
Then, the motivation, life satisfaction, and demographics were assessed. The social-adjustive and value-expressive motivation in buying luxury goods were adapted from the works of Grewal, Mehta, \& Kardes (2004) and Wilcox, Kim, \& Sen (2009), both of which were measured on five-point Likert scales. Social-adjustive motivation was measured on three items (e.g. "Luxury brands are a symbol of social status"; "It is important for my friends to see the luxury brands I posses"; "The luxury brands indicate to others the kind of person I am"; $\alpha=0.71$ ). Value-expressive motivation was measured on three items (e.g. "Luxury brands help me express myself"; "Luxury brands reflect the kind of person I see myself to be"; "Luxury brands make me feel good about myself"; $\alpha=0.77$ ). The life satisfaction was measured by one item on five-point Likert scales ("I am very satisfied with my life"). Demographic data on income, age, education, gender, and residence were also collected.

\section{Results}

A Logistic regression model was used to identify whether the factors play a crucial in affluent consumers luxury purchasing decisions. The model estimates for each consumer the logarithm of the probability of purchasing luxury to not purchasing the luxury. The model is displayed in the following equation:

$$
\operatorname{Logit}(P)=\log \frac{P}{1-P}=\alpha+\sum X_{i} \beta_{i}
$$

Where: $\alpha$ is the constant, and $\beta$ is the coefficients of the independent variable.

Maximum Likelihood Method was used to estimate the model, and the results were presented in Table 2. The Chi-square from the Hosmer and Lemeshow test of the model is 6.06, which is not significant $(\mathrm{p}=0.64)$, indicating the model fits the data well. Moreover, the model could predict a correctness of $76.0 \%$, suggest that the model could satisfactorily explain an individual's decisions to purchase a luxury or not.

Table 2. Variables Coefficients of the Determinants

\begin{tabular}{|c|c|c|c|c|c|}
\hline & $\mathrm{B}$ & $\operatorname{Exp}(B)$ & Wald & df & Sig \\
\hline Social-adjustive Motivation & 0.54 & 1.71 & 12.17 & 1.00 & 0.00 \\
\hline Value-expressive Motivation & -0.25 & 0.78 & 2.18 & 1.00 & 0.14 \\
\hline Life Satisfaction & 0.15 & 1.16 & 6.36 & 1.00 & 0.01 \\
\hline \multicolumn{6}{|l|}{ Income $^{a}$} \\
\hline Less than $200,000 \mathrm{RMB}$ & -2.00 & 0.14 & 18.06 & 1.00 & 0.00 \\
\hline $200,000-300,000 \mathrm{RMB}$ & -1.26 & 0.28 & 8.44 & 1.00 & 0.00 \\
\hline \multicolumn{6}{|l|}{ Age $^{b}$} \\
\hline $20-30$ years old & 0.73 & 2.07 & 4.64 & 1.00 & 0.03 \\
\hline $31-35$ years old & 0.79 & 2.20 & 5.34 & 1.00 & 0.02 \\
\hline $36-45$ years old & 0.99 & 2.68 & 8.45 & 1.00 & 0.00 \\
\hline Education $^{c}$ & 0.76 & 2.14 & 4.99 & 1.00 & 0.03 \\
\hline Male $^{\text {d }}$ & -0.18 & 0.84 & 0.71 & 1.00 & 0.40 \\
\hline \multicolumn{6}{|l|}{ Residence $^{\mathrm{e}}$} \\
\hline Beijing & -0.52 & 0.60 & 2.82 & 1.00 & 0.09 \\
\hline Shanghai & 0.31 & 1.36 & 0.81 & 1.00 & 0.37 \\
\hline Guangzhou & -0.52 & 0.59 & 3.08 & 1.00 & 0.08 \\
\hline Constant & 0.09 & 1.09 & 0.01 & 1.00 & 0.91 \\
\hline
\end{tabular}

a. more than 300,000RMB as reference group; b. older than 45 years old as reference group;

c. domestic education as reference group; d. female as reference group; e. Chengdu as reference group.

From Table 2, the following observations may be observed. The coefficients of social-adjustive motivation is significantly positive, but the impact of value-expressive motivation on luxury consumption is not significant. This is consistent with previous cross-culture luxury consumption studies (Li \& Su, 2007; Wong \& Ahuvia, 1998; Zhan \& He, 2012). Chinese consumers believe they must purchase luxury goods to enhance, maintain or save their "face", thus the social-adjustive motive in purchasing luxury plays a crucial role in the Chinese market. However, they thought the luxury brands did not extend their personal identities much beyond the meanings of status, and had not satisfied their self-expressive needs (Oswald, 2010). Thus, the impact of value-expressive motivation on luxury purchasing is not supported. 
In $\mathrm{H} 3$, we argue that life satisfaction is positively related to luxury purchasing behavior, which was supported as shown in Table 2. If the affluent consumer were satisfied with the life, they would have more propensity to buy luxury goods.

With the demographic characteristics, not surprisingly, income induces individuals to buy luxury, as the income of individual with higher income would be significantly more likely purchase luxury than that with lower income. The results was consistent with that in European market (Dubois \& Duquesne, 1993), and H4 was supported. Also this suggest that even within the affluent consumers, they could be classed into different markets. The individual's age and education play important role in his/her decisions to purchase luxuries. The younger consumer with international education will be more likely to buy luxury goods. H5 and H6 were supported.

The differences between male and female in purchasing luxury goods is not significant. An explanation may be that most of the luxury goods are targeted towards female and most of the products were used by this segment (Stokburger-Sauer \& Teichmann, 2011). However, male could also buy luxury goods, such as husband (non-users) could also buy some luxury as a gift for their wife (Heilman, Kaefer, \& Ramenofsky, 2007). Thus, the purchasing behavior of this two groups are not significant.

We also control the fixed effect of individual residence in the model, and the results demonstrate that consumers' luxury purchasing behavior does not significantly differ with where they live.

\section{Discussion}

The affluent consumers are expanding rapidly in China. It is essential for marketers, especially for luxury brands, to understand the actual purchasing behavior of this market, and design appropriate strategies to meet consumers' needs. This study attempts to provide insights into the determinants of luxury purchasing behavior of this market and most of the hypotheses are supported. The results of the study have suggested that the social-adjustive motivation is positively associated with luxury purchasing behavior, and the impact of value-expressive motivation is not significant.

The life satisfaction is a predictor of luxury purchasing behavior, which have been ignored in previous luxury literature. The demographic characteristics of the affluent consumer were examined in the study. The results demonstrated that income, age, and education of the consumer would have an impact on the luxury purchasing behavior. The younger consumer with higher income and international education would be more likely buy luxury items.

\subsection{Implications for Academic Research}

The results have several contributions to the literature. First, studies examining the actual luxury purchasing behavior are scare. Usually, the luxury research is based on the purchasing intention of the luxury goods. However, the purchasing behavior may be different with purchasing intention, because many factors may have an impact on the buying behavior beyond the purchasing intention. Also the buying behavior of the affluent consumer is not easily surveyed. This study exams the actual luxury purchasing behavior of the affluent Chinese consumer.

Second, China has become one of the most attractive markets for luxury brands in the world. However, the motivation of luxury consumption in other countries could not be generalized to China, because Chinese consumers differ remarkably from their global peers (Zhan \& He, 2012). The results of this study supports this that the value-expressive motivation, which has been verified that could drive the consumer buy luxury items, does not have significant effect on luxury purchasing behavior for the Chinese affluent consumers. This may be happened because Chinese consumers pay more important attention on the "status" of the luxury consumption, or because the global luxury brands advertising has not educate the consumer with the self-expressive value. The study has demonstrated the differences of the luxury consumption motivation between Chinese consumers and their global peers.

Finally, the life satisfaction was included into the luxury purchasing model, which has been ignored in previous luxury research. Generally, life satisfaction may cause luxury purchasing behavior, and luxury buying in turn may lead to life satisfaction, indicating there may be bi-directional relationship between life satisfaction and luxury purchasing behavior.

\subsection{Managerial Implications}

Luxury manufacturers in the West rely on the double-digit growth in emerging markets such as China (Oswald, 2010). To be successful in the luxury market, international luxury brands needs to adjust their plans to fit the market. The results of the study found that social-adjustive motive plays an important role in luxury buying 
decisions, which suggest that luxury brands could be promoted with these social related values. However, the result does not mean that the value expressive is not important. The next generation of the new rich in China expect more of luxury brands than to display their money and success. They expect luxury brands to both express and inform their savoir faire, personality, and taste. They also expect advertising to assist them in learning how to "read" and appreciate brand meanings (Oswald, 2010). That advertising of luxury brand should may contribute both to the social-adjustive and value-expressive value.

Also, the results of the demographic characteristics and life satisfaction offers clear profile of Chinese affluent who could be the marketing target for global luxury brand. The younger consumers, with higher income and international education should be targeted in designing the marketing plans.

\subsection{Limitations and Future Directions}

Despite including a number of determinant variables to explain Chinese affluent consumers luxury purchasing behavior, there could be other variables, such as pre-commitment to indulge (Kivetz \& Simonson, 2002), and social presence (Fransen, Smeester, \& Fennis, 2011), that might increase the explanation of the variance in luxury purchasing. Future research may include more diverse variables in an effort to explain the luxury purchasing behavior of this market.

Moreover, the impact of value-expressive motivation on buying behavior is not significant in this study. As the new generation become the main power of luxury consumption, whether they will focus more on the self-concept in buying the luxuries, still needed to be further investigated.

Finally, we hypothesized that women would be more likely to buy luxuries than men, which was not supported in this study. According to the work of Heilman et al. (2007), men could also buy luxuries, such as husband (non-users) could also buy some luxury as a gift for their wife, it would be interesting to investigate the difference of users and buyers in relation to the luxuries purchasing behavior.

\section{References}

Amaldoss, W., \& Jain, S. (2005). Conspicuous consumption and sophisticated thinking. Management Science, 5l(10), 1449-1466. https://doi.org/10.1287/mnsc.1050.0399

Atsmon, Y., \& Dixit, V. (2009). Understanding China's wealthy. McKinsey Quarterly, 4, 32-33.

Bian, Q., \& Forsythe, S. (2012). Purchase intention for luxury brands: A cross cultural comparison. Journal of Business Research, 65, 1443-1451. https://doi.org/10.1016/j.jbusres.2011.10.010

Chintagunta, P., \& Lee, J. (2012). A pre-diffusion growth model of intentions and purchase. Journal of the Academy of Marketing Science, 40(1), 137-154. https://doi.org/10.1007/s11747-011-0273-2

Cleveland, M., Laroche, M., \& Papadopoulos, N. (2009). Cosmopolitanism, consumer ethnocentrism, and materialism: an eight-country study of antecedents and outcomes. Journal of International Marketing, 17(1), 116-146. https://doi.org/10.1509/jimk.17.1.116

Debnam, N., \& Svinos, G. (2006). Luxury brands in China. Retrieved from http://www.kpmg.de/docs/Luxury_Brands_in_China.pdf

DeBono, K.G. (1987). Investigating the social-adjustive and value-expressive functions of attitudes: Implications for persuasion processes. Journal of Personality and Social Psychology, 52(2), 279-287. https://doi.org/10.1037/0022-3514.52.2.279

Diener, E., Ng, W., Harter, J., \& Arora, R. (2010). Wealth and happiness across the world: material prosperity predicts life evaluation, whereas psychosocial prosperity predicts positive feeling. Journal of Personality and Social Psychology, 99(1), 52-61. https://doi.org/10.1037/a0018066

Dube, L., \& Morgan, M. (1996). Trend effects and gender differences in retrospective judgments of consumption emotions. Journal of Consumer Research, 23, 156-162. https://doi.org/10.1086/209474

Dubois, B., \& Duquesne, P. (1993). The market for luxury goods: income versus culture. European Journal of Marketing, 27(1), 35-44. https://doi.org/10.1108/03090569310024530

Dubois, B., Czellar, S. \& Laurent, G. (2005). Consumer segments based on attitudes toward luxury: Empirical evidence from twenty countries. Marketing Letters, 16(2), 115-128. https://doi.org/10.1007/s11002-005-2172-0

Fransen, M. L., Smeester, D., \& Fennis, B. M. (2011). The role of social presence in mortality salience effects. Journal of Business Research, 64, 29-33. https://doi.org/10.1016/j.jbusres.2009.09.016 
Grewal, R., Mehta, R. \& Kardes, F.R. (2004). The timing of repeat purchases of consumer durable goods: The role of functional bases of consumer attitudes. Journal of Marketing Research, 41(February), 101-115. https://doi.org/10.1509/jmkr.41.1.101.25090

Gu, F., \& Hung, K. (2009). Materialism among adolescents in China: a historical generation perspective. Journal of Asia Business Studies, 3(2), 56-64. https://doi.org/10.1108/15587890980000411

Han, Y. J., Nunes, J. C., \& Drèze, X. (2010). Signaling status with luxury goods: the role of brand prominence. Journal of Marketing, 74, 15-30. https://doi.org/10.1509/jmkg.74.4.15

Heilman, C., Kaefer, F., \& Ramenofsky, S. (2007). Luxury good expenditures of husband and wife dyads incorporating user attitudes. Advances in Consumer Research, 34, 410-411.

Kivetz, R., \& Simonson, I. (2002). Self-control for the righteous: toward a theory of precommitment to indulgence. Journal of Consumer Research, 29, 199-217. https://doi.org/10.1086/341571

Lee, J. H., \& Hwang, J. (2011). Luxury marketing: the influences of psychological and demographic characteristics on attitudes toward luxury restaurants. International Journal of Hospitality Management, 30, 658-669. https://doi.org/10.1016/j.ijhm.2010.12.001

Li, J. J., \& Su, C. (2007). How face influences consumption: A comparative study of American and Chinese consumers. International Journal of Market Research, 49(2), 237-256.

MacLeod, A. K., \& Conway, C. (2005). Well-being and the anticipation of future positive experiences: The role of income, social networks, and planning ability. Cognition and Emotion, 19(3), 357-374. https://doi.org/10.1080/02699930441000247

Mandel, N., Petrova, P. K., \& Cialdini, R. B. (2006). Images of success and the preference for luxury brands. Journal of Consumer Psychology, 16(1), 57-69. https://doi.org/10.1207/s15327663jcp1601_8

Oishi, S., Wyer, R. S. Jr., \& Colcombe, S. J. (2000). Cultural variation in the use of current life satisfaction to predict the future. Journal of Personality and Social Psychology, 78(3), 434-445. https://doi.org/10.1037/0022-3514.78.3.434

Oswald, L. R. (2010). Developing brand literacy among affluent Chinese consumers: a semiotic perspective. Advances in Consumer Research, 37, 413-419.

Podoshen, J. S., Li, L. \& Zhang, J. (2011). Materialism and conspicuous consumption in China: A cross-cultural examination. International Journal of Consumer Studies, 35, 17-25. https://doi.org/10.1111/j.1470-6431.2010.00930.x

Roberts, J. A., \& Clement, A. (2007). Materialism and satisfaction with over-all quality of life and eight life domains. Social Indicators Research, 82, 79-92. https://doi.org/10.1007/s11205-006-9015-0

Segal, B., \& Podoshen, J. S. (2012). An examination of materialism, conspicuous consumption and gender differences. International Journal of Consumer Studies, 37(2), 189-198. https://doi.org/10.1111/j.1470-6431.2012.01099.x

Sekulic, A., \& Sibley, N. (2007). Understanding the affluent consumers of China. Retrieved from http://www.masterintelligence.com/upload/176/110/Affluent_Consumers_China-S.pdf

Shavitt, S. (1989). Products, personalities and situations in attitude functions: implications for consumer behavior. Advances in Consumer Research, 16, 300-305.

Shukla, P., \& Purani, K. (2012). Comparing the importance of luxury value perceptions in cross-national contexts. Journal of Business Research, 65, 1417-1424. https://doi.org/10.1016/j.jbusres.2011.10.007

Stokburger-Sauer, N. E., \& Teichmann, K. (2011). Is luxury just a female thing? The role of gender in luxury brand consumption. Journal of Business Research, 66(7), 889-896. https://doi.org/10.1016/j.jbusres.2011.12.007

Truong, Y. (2010). Personal aspirations and the consumption of luxury goods. International Journal of Market Research, 52(5), 653-671. https://doi.org/10.2501/S1470785310201521

Truong, Y., McColl, R., \& Kitchen, P. J. (2009). New luxury brand positioning and the emergence of Masstige brands. Brand Management, 16(5/6), 375-382. https://doi.org/10.1057/bm.2009.1

Tsai, S. (2005). Impact of personal orientation on luxury-brand purchase value: an international investigation. International Journal of Market Research, 47(4), 429-454. 
Tynan, C., McKechnie, S., \& Chhuon, C. (2010). Co-creating value for luxury brands. Journal of Business Research, 63, 1156-1163. https://doi.org/10.1016/j.jbusres.2009.10.012

Vigneron, F., \& Johnson, L. (1999). A review and a conceptual framework of prestige seeking consumer behavior. Academy of Marketing Science Review, 1, 1-17.

Wiedmann, K., Hennigs, N., \& Siebels, A. (2009). Value-based segmentation of luxury consumption behavior. Psychology \& Marketing, 26(7), 625-651. https://doi.org/10.1002/mar.20292

Wilcox, K., Kim, H. M., \& Sen, S. (2009). Why do consumers buy counterfeit luxury brands? Journal of Marketing Research, 46, 247-259. https://doi.org/10.1509/jmkr.46.2.247

Wong, N. Y., \& Ahuvia, A. C. (1998). Personal taste and family face: luxury consumption in confucian and western societies. Psychology \& Marketing, $15(5), \quad$ 423-441. https://doi.org/10.1002/(SICI)1520-6793(199808)15:5<423::AID-MAR2>3.0.CO;2-9

Workman, J. E., \& Lee, S. (2011). Materialism, fashion consumers and gender: a cross-cultural study. International Journal of Consumer Studies, 35, 50-57. https://doi.org/10.1111/j.1470-6431.2010.00935.x

Wright, M., \& MacRae, M. (2007). Bias and variability in purchase intention scales. Journal of the Academy of Marketing Science, 35(4), 617-624. https://doi.org/10.1007/s11747-007-0049-x

Zhan, L., \& He, Y. (2012). Understanding luxury consumption in China: Consumer perceptions of best-known brands. Journal of Business Research, 65, 1452-1460. https://doi.org/10.1016/j.jbusres.2011.10.011

Zhang, J., \& Shavitt, S. (2003). Cultural values in advertisements to the Chinese X Generation: promoting modernity and individualism. Journal of advertising, 32(1), 23-33. https://doi.org/10.1080/00913367.2003.10639047

\section{Copyrights}

Copyright for this article is retained by the author(s), with first publication rights granted to the journal.

This is an open-access article distributed under the terms and conditions of the Creative Commons Attribution license (http://creativecommons.org/licenses/by/4.0/). 